\title{
Diversidad de origen y socioeconómica en una escuela de Gipuzkoa: diálogo con las familias
}

\section{Diversity of origin and socioeconomic status in a school in Gipuzkoa: dialogue with families}

\author{
Nerea Alzola Maiztegi ${ }^{1}$ \\ nalzola@mondragon.edu \\ Marta Quintas Quintas \\ mquintas@mondragon.edu \\ Nekane Arratibel Insausti \\ narratibel@mondragon.edu \\ Amelia Barquín López \\ abarquin@mondragon.edu \\ Universidad Mondragón, España
}

\section{Resumen:}

El artículo presenta una investigación realizada en una escuela de Gipuzkoa con alta diversidad socioeconómica, de origen y lingüística. Sus objetivos han sido describir, analizar e interpretar las percepciones de las familias sobre dicha diversidad en su propio centro. Se han realizado entrevistas semiestructuradas a familias de distinto origen y analizado los datos mediante el análisis de contenido. Sus voces permiten conocer algunos retos importantes en las relaciones entre las familias y en la calidad educativa de la escuela. Se concluye que el diálogo, el mutuo conocimiento y la educación ética son temas pendientes en la escuela y la sociedad.

\begin{abstract}
:
This article reports on research carried out in a school in Gipuzkoa which is highly diverse socio-economically, linguistically, and in the origin of its pupils. The objectives were to describe, analyze and interpret the perceptions of families about such diversity in their own center. Semi-structured interviews with families of different origin were conducted and the data analyzed using content analysis. Their voices express some important challenges both in the relationships between the families and in the educational quality of the school. It is concluded that dialogue, mutual knowledge and ethical education are pending issues at school and in society.
\end{abstract}

1 Dirección para correspondencia (correspondence address):

Nerea Alzola Maiztegi. Huhezi (Facultad Humanidades y Ciencias de la Educación). Mondragon Unibertsitatea - Universidad Mondragón. Dorleta s/n - 20540 Eskoriatza (España). 
Diversidad de origen y socioeconómica en una escuela de Gipuzkoa: diálogo con las familias

Nerea Alzola Maiztegi, Marta Quintas Quintas, Nekane Arratibel Insausti y Amelia Barquín LÓPEZ

\section{Palabras clave:}

Familia; diversidad; escuela inclusiva; educación intercultural.

\section{Keywords:}

Family; diversity; inclusive school; intercultural education

\section{Résumé:}

L'article présente une recherche faite dans une école de Gipuzkoa avec une haute diversité socio-économique, d'origine et linguistique. Les objectifs de cette recherche sont de décrire, analyser et interpréter les perceptions des familles sur la diversité de leur propre école. Des entretiens semi-structurés ont été menés avec des mères et des pères d'origines différentes, analysant les données par le moyen d'une analyse de contenu. Cette étude permet de déduire les défis les plus importants pour l'amélioration des relations entre les familles et de la qualité éducative de l'école. Nous conclurons que le dialogue, la connaissance mutuelle et l'éducation éthique sont des sujets à travailler à l'école et dans nos sociétés.

\section{Mots-clés:}

Famille; diversité; école inclusive; éducation interculturelle.

Fecha de recepción: 21-02-2019

Fecha de aceptación: 14-12-2019

\section{Introducción}

La equidad es un importante reto social y educativo, pues es una evidencia que determinados grupos de población se quedan atrás en la escuela y, por consiguiente, en la sociedad. Ello supone un fracaso en sí mismo con importantes repercusiones en las vidas de las personas (Save the Children, 2018).

Numerosas investigaciones corroboran que las desigualdades nacen en buena medida de una pedagogía poco sensible a la heterogeneidad del alumnado (Bourdieu y Passeron, 1970; Bernstein, 1988; 1989; Demeuse, Frandji, Greger y Rochex, 2012). La OCDE ha publicado recomendaciones para luchar contra el fracaso escolar, ha impulsado el debate político sobre la equidad y ha defendido programas escolares para el éxito escolar de todo el alumnado (OCDE, 2018). No podemos olvidar que el índice socioeconómico y cultural de las familias influye en el éxito académico (Cebolla Boado, 2014).

Asimismo, diversos estudios (Flores, 2016; ISEI-IVEI, 2018; Murillo y Martínez-Garrido, 2018) confirman que la discriminación escolar por nivel socioeconómico es uno de los desafíos del sistema educativo. La probabilidad de acceso a una educación de calidad es menor en las escuelas segregadas (Santos Rego y Lorenzo, 2015). 
El fenómeno de la inmigración ha incrementado significativamente la diversidad del alumnado y los resultados académicos son considerablemente más bajos entre la población escolar de origen inmigrante (Fundación Encuentro, 2015; Ikuspegi, 2017; ISEI-IVEI, 2018).

Por otra parte, la llegada de personas con distintas creencias ha originado que la cuestión religiosa se haya convertido en pieza estratégica para rehacer el entramado de la convivencia (Lippy, 2009). Aunque las sociedades occidentales han comenzado a dejar de lado lo religioso (Habermas, 2006), muchas familias solicitan que su religión sea respetada y considerada en la escuela. En una sociedad cada vez más secularizada, una educación inclusiva no puede dejar de lado la diversidad religiosa en la vida escolar (Álvarez y Essomba, 2012).

Sin negar la influencia del factor familia (Fundación "la Caixa", 2010), hay cada vez más investigaciones sobre el impacto que tiene la escuela para la promoción de la equidad e inclusión educativas (Pàmies y Bertrán, 2015). Esta puede conseguir que todo el alumnado, aunque proceda de medios desfavorecidos, logre un buen éxito escolar: "Our school systems have the potential to catalyze opportunity, but that potential is incompletely realized in many places $[. .$.$] and poverty very clear does$ not strictly determine the opportunities for children to learn [...]" (Stanford CEPA, 2018, p. 32).

La intervención pedagógica ajustada a las distintas necesidades del alumnado se convierte en un mecanismo preventivo en los procesos de pobreza y exclusión social (Save the Children, 2015). Existen escuelas en las que el alumnado con dificultades de partida tiene la oportunidad de alcanzar el éxito escolar, por lo que es posible crear escuelas equitativas (Stanford CEPA, 2018). Algunos estudios (Ainscow, 2010; Riehl, 2000; Pàmies y Bertrán, 2015; Debarbieux, 2017) concluyen que claves del éxito en escuelas en entornos desfavorecidos son, entre otros, la cultura institucional y, especialmente, el sentimiento de pertenencia, la confianza de las familias y su implicación y la calidad de las relaciones interpersonales.

Por lo tanto, la comunidad educativa tiene que construir el proyecto educativo intercultural con el compromiso de todos los agentes, incluidas las familias (Unicef, 2011; Hopson y Lee, 2011; Banks, 2014; Florin y Guimard, 2017) y fomentar la implicación familiar impulsando el sentimiento de pertenencia (Intxausti, 2010). Diversos estudios señalan la importancia de que las familias se sientan reconocidas, responsables 
Nerea Alzola Maiztegi, Marta Quintas Quintas, Nekane Arratibel Insausti y Amelia Barquín LÓPEZ

(Gomariz, Hernández, Parra y García, 2015; Ladrón de Guevara, 2018), bienvenidas y valoradas en el centro (Simón, Giné y Echeita, 2016).

La institución escolar debe ser un lugar para la convivencia intercultural (Blanco e Hidalgo, 2013; Espinosa y Pérez, 2013), donde las personas de distintos orígenes tengan espacios de interrelación (Canto, 2010; Perea y López, 2010) y donde la relación que se fomente sea de respeto e igualdad, pues según Allport (como se citó en Perea y López, 2010), solo así pueden eliminarse los estereotipos.

Si la participación y el diálogo entre diferentes son claves para dar cohesión a la comunidad escolar (Leiva y Escarbajal, 2011) y para una educación justa (Zay, 2012), la relación entre escuela y familia (Carrasco, Pàmies y Beltrán, 2009; Etxeberria, Intxausti y Joaristi, 2013; Collet-Sabé, Besalú, Feu y Tort, 2014) y la relación que se establece entre las familias (Castro, Expósito, Lizasoain, López y Navarro, 2014) son factores clave para la calidad del centro y el éxito de todo el alumnado.

Como ya hemos indicado, la literatura científica ha mostrado que el alumnado en desventaja tienen menor éxito escolar, pero también que es posible revertir esa situación y que uno de los factores para ello es la relación entre las familias y la escuela y, dentro de ella, la relación entre las propias familias. Por ello nos parece necesario conocer qué piensan y sienten las familias en torno a la diversidad de su propio centro, tanto la de origen como la socioeconómica y cultural. El objetivo que se planteó nuestra investigación fue el describir, analizar e interpretar las percepciones de las familias de una escuela de Gipuzkoa sobre la diversidad socioeconómica y de origen de su propio centro. Nuestro propósito fue contribuir al conocimiento de aquello que pudiera ser relevante para la mejora de las relaciones entre las familias, factor que influye en la relación familia-escuela y en la calidad educativa.

\section{Metodología}

La investigación se realizó en una escuela pública de una población importante de Gipuzkoa. El 9,56\% de la población del municipio ha nacido en el extranjero y la comunidad mayoritaria es de origen marroquí (el 2,81\%) (Eustat, 2017). Se ha elegido esta escuela por su diversidad de origen y por la situación socioeconómica desfavorecida de muchas familias. 
El $65 \%$ del alumnado ha nacido en familias que proceden de fuera del Estado español (el $44 \%$ es de origen magrebí) y hay 15 lenguas familiares en el centro. El $84 \%$ del alumnado recibe beca, lo que indica que el nivel socio-económico de muchas familias es bajo. Algunas familias sufren pobreza energética.

La dirección contactó con familias que cumplieran el perfil apuntado (diversidad de origen, lingüística y socio-económica) y se entrevistó a las personas que accedieron. En total han sido 17 madres ( 7 de origen extranjero) y un padre autóctono. Todas estas personas tienen una relación fluida con el profesorado y se comprometen en los órganos de participación y en las actividades del centro. Que casi todas sean madres responde a una realidad bien conocida de muchas escuelas, donde son mayoritariamente las mujeres quienes se implican en ellas.

La investigación es de carácter cualitativo, dentro del paradigma socio-crítico (Habermas, 1988; 1994). Los datos se han recopilado a través de entrevistas semi-estructuradas por su capacidad para recoger los pensamientos, sentimientos y emociones de las personas (Del Rincón, La Torre, Arnal y Sanz, 1995). Las investigadoras han procurado crear una atmósfera de confianza para que las personas participantes se sintieran seguras y con libertad para expresarse (Hernández, Fernández y Baptista, 2014).

El guión constó de los siguientes apartados: la opinión de las familias sobre la escuela y la importancia que le otorgan; el uso cotidiano e importancia de las lenguas en casa; el contacto entre familia y escuela; las amistades de sus hijos e hijas; el origen del alumnado de la escuela; las lenguas y culturas de origen y su tratamiento en la escuela; la situación socio-económica de las familias.

Las entrevistas se realizaron en un aula de la escuela, todas en castellano excepto una en euskera, y duraron entre 45 y 90 minutos, todas grabadas en audio. Se hicieron cuatro entrevistas individuales y cinco entrevistas grupales (de entre 2 y 3 personas). Los criterios que se tuvieron en cuenta para los grupos fueron la relación de amistad entre las participantes.

Los datos se han analizado mediante el análisis de contenido, según las etapas descritas por Ruiz Olabuénaga (1999). Se ha utilizado el software Atlas.ti (versión 7.5.18) para el análisis de las transcripciones.

Para garantizar la fiabilidad se llevó a cabo un diseño de reproducibilidad que requiere, al menos, de dos observadores y un acuerdo de un 
Diversidad de origen y socioeconómica en una escuela de Gipuzkoa: diálogo con las familias

Nerea Alzola Maiztegi, Marta Quintas Quintas, Nekane Arratibel Insausti y Amelia Barquín LÓPEZ

85\% (Nieto y González, 2002). Para ello, cuatro investigadoras analizaron individualmente una entrevista y realizaron una primera categorización, para verificar la sistematización del análisis. El acuerdo obtenido fue del 90\%. Una vez consensuadas las categorías dos investigadoras realizaron el análisis de las demás entrevistas, reuniéndose semanalmente para comparar y homologar los fragmentos de texto categorizados, siguiendo a Creswell (2009).

Una vez transcritas y analizadas las entrevistas, en el curso 20172018 se expusieron los resultados obtenidos tanto al claustro como a las familias. Se verificó que los resultados recogían todas las sensibilidades y lo que las familias querían expresar (Hernández et al., 2014). A partir de una convocatoria a todas las familias para un seminario de reflexión, 12 madres y dos investigadoras se han reunido regularmente durante los cursos académicos 2017/18 y 2018/19. De este modo hemos tenido oportunidad de profundizar en sus reflexiones y observar la evolución de sus percepciones. Por lo tanto, aunque en el artículo exponemos los resultados de las entrevistas, en las conclusiones podemos ofrecer también pistas surgidas en ese diálogo durante los encuentros posteriores.

\section{Resultados}

Las categorías que emergieron del análisis son las siguientes: 1) Percepción de las familias hacia la diversidad de origen, 2) Percepción de las familias de origen extranjero sobre la actitud en el pueblo, 3) Tratamiento de la diversidad de origen en la escuela, 4) Tratamiento de la diversidad de origen en casa, 5) Percepciones sobre la desventaja económica, 6) Estereotipos sobre las familias de origen extranjero, 7) Diversidad cultural y religiosa en la escuela, 8) Valores y comportamientos de las familias de origen extranjero (desde la mirada autóctona), 9) Desacuerdos entre familias de origen extranjero y autóctono, 10) Preocupaciones y peticiones de las familias en la escuela.

"Percepción de las familias hacia la diversidad de origen". Las familias manifiestan aspectos positivos: sus hijas e hijos tienen la oportunidad de vivir realidades diversas y desarrollar una perspectiva no eurocéntrica (3 personas); de adquirir conocimientos en contacto con alumnado de otros orígenes (2); de crecer sin prejuicios (1). 
Asimismo, 2 personas autóctonas valoran el esfuerzo cultural y económico que hacen las familias de origen inmigrante para que sus hijos e hijas vivan la cultura vasca.

Es algo que valoro muchísimo de la gente que no ha nacido aquí, que no es su cultura, que hagan un esfuerzo y compren el traje típico a los niños para fiestas determinadas. (MA 4)

Las personas entrevistadas hacen referencia a dos aspectos preocupantes. Por un lado, el $65 \%$ de las familias proviene del extranjero, en especial del Magreb, y ello tiene consecuencias negativas: la escuela se ha convertido en un gueto (12 personas); existen dificultades para hacer amistades entre personas de distintos orígenes (11); algunas autóctonas se sienten en minoría (2). Por otro lado, 5 personas de origen magrebí detallan situaciones de discriminación vividas.

En las áreas de juegos [...] hay algunos que no dejan a sus hijos jugar con un extranjero; sí, eso pasa [...]. (MI 1)

Asimismo, 11 personas indican que el alumnado entiende y acepta la diversidad; son las personas adultas las que transmiten los estereotipos.

La niña no hace diferencias, pero según crezca las irá apreciando cada vez más. No por ella sino por las familias que le van transmitiendo eso. (MA 6, traducido del euskera)

\section{"Percepciones de las familias de origen extranjero sobre la actitud en} el pueblo". Las 5 personas de origen marroquí hablan sobre actitudes de rechazo de la población: dificultad para alquilar viviendas, la desconfianza del vecindario y las dificultades para encontrar un trabajo acorde al nivel de estudios.

Escriben no queremos marroquíes [...] en las paredes [...] en el parque. (MI 2)

2 Hemos suprimido los nombres para mantener el anonimato de las personas participantes. MA significa madre autóctona, MI madre de origen inmigrante y PA padre autóctono. 
Diversidad de origen y socioeconómica en una escuela de Gipuzkoa: diálogo con las familias

Nerea Alzola Maiztegi, Marta Quintas Quintas, Nekane Arratibel Insausti y Amelia Barquín LÓPEZ

Al mismo tiempo, 3 de esas personas expresan que los medios de comunicación promueven el racismo y los estereotipos, lo que no facilita su integración.

En la tele siempre los musulmanes son terroristas [...], los musulmanes son gente mala. (MI 3)

"Tratamiento de la diversidad de origen en la escuela". Las familias hacen referencia a aspectos culturales, religiosos y lingüísticos. 6 personas mencionan de manera positiva la denominada "fiesta de las familias" por la alta participación de familias de origen inmigrante y por el clima logrado.

Hicimos un encuentro de familias, y cada uno aportó algo de su cultura. [...].

Se presentó mucha gente, más gente de fuera que de aquí. (PA)

Además, las familias citan dos actividades que el profesorado ha integrado en el currículum escolar: una sobre diferentes religiones (2 personas); otra con el mapamundi para trabajar el origen del alumnado (1).

- [... ] Alguna vez han hecho algún mural de Budismo, Islam y todo eso.

- Sí, en la clase de religión. (MA 4 y MA 5)

1 persona de origen magrebí ha comenzado a narrar cuentos en árabe en la clase de su hija.

Cuento un cuento en árabe [...]. Es algo para que los niños ser felices. (MI 4)

Se siguen celebrando las fiestas tradicionales. Sin embargo, las fiestas más importantes para las familias de otros orígenes siguen sin ser reconocidas (2 personas). Por ejemplo, la Fiesta del Cordero:

- Ellos [los musulmanes] celebran el día del cordero [...]

- Ese día los más religiosos no vienen a la escuela. (MA 1 y MA 2)

"Tratamiento de la diversidad de origen en casa". 2 personas intentan trabajar la diversidad en casa, principalmente para responder a las preguntas de sus hijos e hijas. 
1 persona manifiesta la necesidad de trabajar activamente en casa para que sus hijas e hijos piensen críticamente y no den por sentadas las percepciones actuales de la sociedad.

¿Por qué dices eso? Sí, es marroquí, como si fuera francés y me da igual de dónde sea, pues, ¿ipor qué los marroquíes son distintos? [...] Mi hijo nunca escuchará en casa algo malo sobre alguien de otra nacionalidad. (MA 6, traducido del euskera)

Las familias de origen inmigrante se inquietan porque sus hijos e hijas nacidos en la sociedad de acogida no son considerados ciudadanos plenos. Aunque las familias quieren que logren sus derechos conservando la propia marca de identidad, encontramos a 1 persona que desiste.

Mi hijo mayor me dice [...] - mami ¿yo soy marroquí o español? - tú eres español - no, es que en el cole me dicen, somos españoles y tú eres marroquí - [...]. Le he dicho que él ha nacido en España, entonces es español, que se olvide de Marruecos. (MI 2)

"Percepciones sobre la desventaja económica". En pocas entrevistas se manifiesta la conciencia de la situación de muchas familias de la escuela. 1 persona expresa que los niños y niñas perciben la situación de desventaja.

Los niños empiezan a darse cuenta y a sentir pena, no salen nunca, nunca van a ningún sitio. Y ¿por qué no van? (MA 6, traducido del euskera)

Se mencionan las facilidades de financiación: por ejemplo, las excursiones y la cuota del AMPA se pueden pagar a plazos (4 personas). 1 persona detalla las ayudas económicas: la existencia de becas (comedor y material), el AMPA paga el autobús de las excursiones y las actividades municipales son gratuitas para perceptores de la RGI.

"Estereotipos sobre las familias de origen extranjero". Las 5 personas de origen marroquí escuchan rumores sobre su colectivo. También 3 de ellas explican que los medios de comunicación tienen gran parte de responsabilidad. 
Diversidad de origen y socioeconómica en una escuela de Gipuzkoa: diálogo con las familias

Nerea Alzola Maiztegi, Marta Quintas Quintas, Nekane Arratibel Insausti y Amelia Barquín LÓPEZ

Dicen, los marroquíes no quieren trabajar, son malos, solamente quieren cobrar las ayudas. Esto leo también en los periódicos. (MI 2)

Por otro lado, familias autóctonas citan estereotipos extendidos sobre las personas de origen inmigrante: se aprovechan de las ayudas sociales (6 personas); el alumnado recién Ilegado hace descender el nivel académico del centro (3); no aportan nada (2); no hablan euskera (1).

¡Con lo que nos ha costado a nosotros aprender euskera y conseguir que en nuestra casa se hable en euskera, ahora se van a juntar con todos los extranjeros! (MA 2)

- [...] entran otros nuevos, y entran otros, y entran otros. El grupo es muy difícil que se consolide, pues eso a mí ahora me da qué pensar [...]. Yo digo el nivel académico ¿hasta qué punto va a funcionar?, ¿no?

- Y no solo cada año, también te vienen a mitad de curso. (MA 7 y MA 8)

\section{"Diversidad cultural y religiosa en la escuela". 3 personas autóctonas} desean conocer los diversos modos de vida y las tradiciones culturales de todas las familias.

La educación religiosa es un tema de debate en la escuela. 3 personas, de tradición católica, señalan que las familias musulmanas han pedido que se trabaje el Islam en el centro. Entienden que, si se imparte la religión católica, también debe haber opción al Islam.

Asimismo, existen desencuentros en la escuela relacionados con la diversidad cultural y religiosa: 3 personas mencionan la resistencia de las familias musulmanas a participar en actividades y fiestas del centro por un choque con su práctica religiosa. 2 personas autóctonas critican que algunas familias musulmanas recelen que no se respeten sus tradiciones religiosas, como la comida halal.

- Hay algunas madres musulmanas que tampoco quieren participar porque [...] esas fiestas las ven como una falta a su religión.

- Aunque la maestra decía pues mira tiene esos ingredientes, puede comer. Pero la madre estuvo muy atenta, diciéndole al niño que comiera solo lo que habían llevado de casa. (MA 4 y MA 5) 
Nerea Alzola Maiztegi, Marta Quintas Quintas, Nekane Arratibel Insausti y Amelia Barquín

1 persona autóctona expresa la discrepancia existente sobre el menú al que puede optar el alumnado musulmán. Hay familias que no aceptan que puedan elegir menú.

Sobre el asunto de la comida, la gente dice: a ellos siempre se les da comida especial. Y yo les digo, ino!, jla vegetariana! (MA 6, traducido del euskera)

"Valores y comportamientos de las familias de origen extranjero (desde la mirada autóctona)". 3 personas creen que las musulmanas que mantienen más sus costumbres (especialmente el modo de vestir) son más introvertidas y no se esfuerzan en la convivencia.

Hay diferencias [...] simplemente por la manera de vestir. [...] Hay algunas que les ves con ese vestido, que no sé como se llama, pero que tapa la ropa que llevan debajo, son como más introvertidas. (MA 10)

Esas mismas personas subrayan que las familias musulmanas dejan menos libertad a sus hijas adolescentes y se relacionan menos entre chicos y chicas.

Han sido niñas que se han criado en la calle [...]. Y de repente, dejaron de venir. [...] Ahora nuestras hijas son más mayores [...] y ya les dejamos un poco más. A ellas no les dejan bajar a la calle más lejos con sus amigas. (MA 9)

\section{"Desacuerdos entre familias de origen inmigrante y autóctono". Algu-} nos han sido mencionados anteriormente: no querer participar en actividades y fiestas del centro por ir en contra de su religión, la desconfianza de algunas a que el profesorado respete sus costumbres y los menús.

A 4 de las 5 personas marroquíes les preocupa que sus hijas e hijos no aprendan árabe, y por ello mencionan la importancia de clases particulares. Ante ello, 1 persona autóctona señala la separación que puede ocasionar el asistir a extraescolares diferentes.

[...] para que no olvidemos la lengua materna, necesitamos ayuda. La niña fue el sábado y el domingo por la mañana para las clases de árabe [...]. (MI 4) Ya con 6 años los autóctonos se quedan jugando en el patio y todos los marroquíes a clases de árabe. Así se empiezan a remarcar las diferencias desde que son pequeños. (MA 6, traducido del euskera) 
Diversidad de origen y socioeconómica en una escuela de Gipuzkoa: diálogo con las familias

Nerea Alzola Maiztegi, Marta Quintas Quintas, Nekane Arratibel Insausti y Amelia Barquín LÓPEZ

"Peticiones y preocupaciones de las familias en la escuela". A 9 personas les preocupan los grupos de amistad que se crean y la separación entre alumnado de origen magrebí y el resto, que se hace más evidente según se hacen mayores.

Mi hijo siempre ha tenido en su clase a más gente musulmana que de aquí. Nunca ha tenido problema y, ahora que se va haciendo mayor, a veces me habla de "esos marroquíes". (MA 4)

A las personas autóctonas no les importa que tengan amistades de otros orígenes, pero a 7 de ellas les preocupa que sean las únicas, y a 1 le preocupa que por ello no cultiven las tradiciones vascas.

Los amigos de mi hijo siempre son importantes. Me da lo mismo de donde sean, pero claro isi todos son árabes! Yo quiero que mi hijo mantenga su cultura. Que tenga amigos árabes, sí, pero que todos sean árabes, pues no. (MA 6 , traducido del euskera)

Las 5 personas de origen marroquí señalan que las familias transmiten a sus hijos e hijas sus prejuicios y 6 personas autóctonas lo confirman.

Las 5 personas de origen marroquí quieren que en la escuela se viva en respeto. Existe una preocupación por la educación en valores, base de la convivencia.

El respeto es lo más importante: respeto entre los niños, las familias, los alumnos, los profesores, todo. [...] En la escuela hay falta de respeto. (MI 4)

Esas mismas personas desean que sus hijos e hijas consigan un buen nivel en euskera y para ello solicitan ayuda a la escuela. Asimismo, piden más clases de euskera para las personas adultas.

Igualmente, a esas 5 personas les intranquiliza su dominio del casteIlano. Ven la necesidad de crear espacios para practicarlo, ya que en su vida diaria mayoritariamente se relacionan solo entre ellas.

- Tenemos que hacer como un café [...] una vez a la semana para practicar, si no, estamos en casa o solo con árabes, y en esas situaciones hablamos en árabe.

- Porque para practicar el español, nos falta que haya españoles con nosotros ¿dónde están?, ¿cuándo están los españoles con nosotros? (MI 3 y MI 5) 
Al mismo tiempo, 10 personas reclaman más recursos, más relaciones con diferentes agentes como los servicios sociales y más profesorado para asegurar una buena educación.

Recursos [...], dinero, para comprar más material, más libros, más ordenadores. Pero eso ya no está en manos de la escuela. (MA 1)

Se detectan también preocupaciones ya mencionadas en categorías anteriores: la guetización de la escuela, el difícil desarrollo de la identidad de las y los hijos y el nivel académico de la escuela.

\section{Discusión}

- La diversidad es percibida positivamente y se considera que puede favorecer el desarrollo de una mentalidad abierta, el enriquecimiento mutuo y un mejor conocimiento de la complejidad del mundo y sus culturas. Las familias quieren que la escuela sea un espacio donde exista una interrelación entre sujetos de culturas distintas (Blanco e Hidalgo, 2013).

Aunque todas las personas consideran la pluralidad como una riqueza, no saben o no están dispuestas a crear esos espacios comunes; cada grupo cultural queda aparte y recelan unos de otros por los estereotipos existentes. Se conforman con eventos puntuales, anecdóticos.

Al mismo tiempo, manifiestan preocupación por el hecho de que el $65 \%$ del alumnado provenga de fuera del Estado, en especial del Magreb. Es decir, les inquieta la concentración de inmigrantes, preocupación compartida con muchos agentes sociales, políticos y educativos.

Además, las familias de origen magrebí sufren experiencias discriminatorias, tanto en la escuela como en el pueblo, algunas de ellas ya enumeradas por Canto (2010).

- Las familias señalan que en la escuela circulan estereotipos sobre las personas inmigrantes (el cobro de ayudas sociales, el bajo nivel de euskera, el bajo rendimiento académico y la resistencia a la integración). Son estereotipos también detectados en general en la Comunidad Autónoma Vasca (Ikuspegi, 2018). 
Nerea Alzola Maiztegi, Marta Quintas Quintas, Nekane Arratibel Insausti y Amelia Barquín

Las madres de origen magrebí se sienten criticadas principalmente por dos aspectos: el cobro de ayudas sociales y el hecho de ser musulmanas. Allport (como se citó en Perea y López, 2010) señala que el contacto basado en el respeto e igualdad de estatus podría disminuir los estereotipos.

Algunas familias autóctonas critican comportamientos de determinadas familias de origen magrebí (escasa comunicación, código de vestimenta, educación de las chicas, dificultad de relaciones entre adolescentes...). Sin embargo, no ponen en tela de juicio sus propias prácticas educativas. No obstante, una de las tareas de la ética es potenciar la crítica en el interior de cada cultura para capacitar incluso para la desobediencia cultural.

- Las familias muestran poca información sobre el trabajo referente a la educación intercultural en el centro. Podemos leer este hecho desde dos perspectivas, sin saber cuál es la más cercana a la realidad: o bien las familias entrevistadas apenas conocen los proyectos que se realizan en la escuela o bien ocurre que en la escuela no se trabaja en dicha educación.

La diversidad se aborda de manera folclórica, con los riesgos que ello conlleva. Se pueden llegar a afianzar los estereotipos existentes, ya que las culturas familiares se perciben como algo monolítico e inamovible y reducido a unos pocos rasgos superficiales (Coelho, 2006; Leiva, 2015).

- La cuestión religiosa suscita interés. Las familias musulmanas piden reconocimiento del Islam y, en consecuencia, algunas familias de tradición cristiana toman conciencia de que un conocimiento mutuo ayudaría a la convivencia en la escuela.

De todos modos, la cuestión religiosa es un punto de desencuentro entre las familias musulmanas y el profesorado. Las sociedades occidentales han sido alcanzadas por la secularización y ello ha supuesto un imaginario de progreso que margina lo religioso (Habermas, 2006). El profesorado de la escuela está también inmerso en esa corriente y le falta formación en este terreno.

- Una preocupación principal de las familias es el entramado de relaciones de sus hijos e hijas. Aceptan la amistad con personas de distintas procedencias, pero las autóctonas sienten miedo de que su prole se convierta en grupo minoritario. Tras esta inquietud quizá se esconde la preocupación por el futuro social de sus hijos e 
hijas. Cortina (1993) formula algunas cuestiones candentes sobre el tema: con esas amistades, ¿triunfarán en la vida?, ¿serán felices?, ¿no les conviene tener amistades bien situadas socialmente?

Asimismo, las familias constatan que, a medida que crecen, las niñas y las niños se van dividiendo en dos grupos: el alumnado magrebí y el resto.

- Hay familias en riesgo de exclusión si tenemos en cuenta el número de becas y la información dada por las familias. Incluso, en conversaciones con el profesorado sabemos que algunas familias sufren pobreza energética, elemento que condiciona de modo importante el bienestar y el desarrollo del alumnado.

No podemos olvidar que el índice socioeconómico y cultural de las familias influye en el éxito académico del alumnado. ISEI-IVEI (2018) concluye que en las escuelas del País Vasco la diferencia en los resultados entre el alumnado en ventaja y desventaja se ha incrementado desde 2015. Sin embargo, el efecto escuela impacta en la promoción de la equidad.

- Las madres de origen magrebí apuntan que en la sociedad de acogida no se trabajan suficientemente los valores. Todas las personas entrevistadas concuerdan en la necesidad de promover comportamientos éticos, especialmente el respeto.

- A las familias de origen magrebí les preocupa el aprendizaje del euskara y del español (lenguas oficiales), y del árabe para sus hijos e hijas. En el caso de las lenguas oficiales desearían contar con la ayuda de la comunidad escolar, tanto para sus hijas e hijos como para ellas mismas.

La preocupación respecto al euskera es comprensible, pues el sistema educativo actual, como señala ISEI-IVEI (2018), no puede asegurar el dominio del euskera en algunos contextos sociolingüísticos donde esta lengua es minoritaria.

Con respecto al árabe, las familias buscan soluciones fuera de la escuela (casa, mezquita, etc.), pero temen que sus hijas e hijos no lleguen a dominar la lengua familiar. No demandan a la escuela ayuda para ello, pero no podemos olvidar que el reconocimiento de las lenguas familiares es clave para la educación intercultural (Coelho, Serra y Oller, 2013). Asimismo alguna familia autóctona señala que ir a clases de árabe provoca una división entre el alumnado, sin analizar las diferencias existentes en la organización del ocio. 
Nerea Alzola Maiztegi, Marta Quintas Quintas, Nekane Arratibel Insausti y Amelia Barquín LÓPEZ

- Otra preocupación entre las familias de origen magrebí es el desarrollo de la identidad de sus hijos e hijas. Desean que su prole desarrolle una identidad múltiple, es decir, que puedan sentirse plenamente tanto de su lugar de procedencia como de la sociedad local (Maalouf, 1999). Sin embargo, son conscientes de la dificultad que ello conlleva.

\section{Conclusiones}

La diversidad de las familias de esta escuela es una realidad positiva para ellas mismas (lengua, religión, valores, educación de los hijos e hijas...). Ello supone una gran riqueza, pero existe el reto de organizar espacios de escucha y conocimiento mutuos, de diálogo, de construcción de un suelo común, de convivencia, etc. Uno de los retos de la escuela es el fomento de relaciones respetuosas y horizontales entre familias de procedencias diversas. Además, para algunas personas de origen inmigrante la escuela es el primer y único espacio en el que pueden relacionarse con el colectivo autóctono.

Desarrollar proyectos de carácter intercultural que contribuyan a superar el etnocentrismo, la xenofobia y promuevan las competencias interculturales es una prioridad. Las familias y profesorado deben crear espacios para trabajar la dimensión afectiva y ética del alumnado, como bases de la convivencia.

La educación intercultural es un aspecto importante que la formación inicial y permanente del profesorado necesita tratar seriamente, también en aquellos aspectos relacionados con las familias. Asimismo, en una cultura en la que lo religioso ha ido perdiendo relevancia, es necesario en esa formación abordar y reflexionar sobre el hecho religioso, su pluralidad y su gestión en los centros.

La preocupación por el conocimiento de las lenguas oficiales -y del euskera en particular como lengua minoritaria- se convierte en un reto importante para la comunidad escolar. Al mismo tiempo no podemos olvidar que el reconocimiento de las lenguas familiares en la escuela es clave para la educación intercultural.

A partir de la relación creada durante las entrevistas, nos hemos reunido periódicamente durante dos años con 12 personas de origen distinto, a las que se han añadido dos miembros de la dirección y una profe- 
Nerea Alzola Maiztegi, Marta Quintas Quintas, Nekane Arratibel Insausti y Amelia Barquín

sora. Los temas se han hablado con libertad, y ha resultado ser un medio importante para la creación de una comunidad inclusiva. Durante las tertulias se ha creado un espacio común, de escucha y discusión, entre familias y entre familias y profesorado.

Este tipo de espacios puede permitir el avance en la de-construcción de los prejuicios y la creación de un clima cordial. Es una cuestión que exige formación y dedicación de las y los adultos, tanto docentes como familias, así como investigación, reflexión y medidas administrativas. La comunidad escolar debe mostrar a cada miembro, y también a las familias, en tantos casos silenciadas, que su palabra es importante.

Las familias entrevistadas, cercanas a la escuela, son de gran valor y fuente de conocimiento, pero no hemos podido acceder a las familias más desfavorecidas y alejadas del centro. Superar esta dificultad de acceso constituye un reto para próximas investigaciones.

Si la diversidad del alumnado y la inclusión representan cada vez más desafíos para los profesionales de la educación (Ainscow y Sandill, 2010), este trabajo de creación de convivencia necesita voluntad política (Freire, 1993), planificación fundada en el respeto a las diferencias (Verdeja, 2016) e impulsar el pensamiento crítico y ético en los procesos de formación (Torralba, 2018-11-23).

\section{Referencias}

Ainscow, M. (2010). Achieving excellence and equity: reflections on the development of practices in one local district over 10 years. School Effectiveness and School Improvement, 21(1), 75-92. doi:10.1080/09243450903569759

Ainscow, M., \& Sandill, A. (2010). Developing inclusive education systems: the role of organizational cultures and leadership. International Journal of Inclusive Education, 14, 401-416. doi: 10.1080/13603110802504903

Álvarez, J. L., y Essomba, M. À. (Eds.). (2012). Dioses en las aulas: educación y diálogo interreligioso. Barcelona, España: Graó.

Banks, J. A. (2014). Diversity, group identity, and citizenship education in a global age. Journal of Education, 194(3), 1-12. doi: 10.1177/002205741419400302

Bernstein, B. (1988). Clases, códigos y control II. Hacia una teoría de las transmisiones educativas. Madrid, España: Akal.

Bernstein, B. (1989). Clases, códigos y control I. Hacia una teoría de las transmisiones educativas. Madrid, España: Akal.

Blanco, V., e Hidalgo, A. (2013). Pasapalabras intercultural: Conocimiento y convivencia. En M. T. Castilla, V. M. Martín, E. S. Vila, y A. M. Sánchez. (Eds.), Educación 
Diversidad de origen y socioeconómica en una escuela de Gipuzkoa: diálogo con las familias

Nerea Alzola Maiztegi, Marta Quintas Quintas, Nekane Arratibel Insausti y Amelia Barquín LÓPEZ

y cultura de paz en contextos educativos (pp. 74-83). Granada, España: Editorial GEU.

Bourdieu, P., et Passeron, J-C. (1970). La Reproduction. Éléments pour une théorie du système $d^{\prime}$ enseignement. Paris, France: Les éditions de Minuit.

Canto, A. (2010). Familias inmigrantes asentadas en la CAPV: los caminos hacia la integración. Inguruak. Revista vasca de sociología y ciencia política, extra 0, 95-108. Recuperado de https://dialnet.unirioja.es/servlet/articulo?codigo=5045828

Carrasco, S., Pàmies, J., y Bertrán, M. (2009). Familias inmigrantes y escuela: Desencuentros, estrategias y capital social. Revista Complutense de Educación, 20(1), 55-78.

Castro, M., Expósito, E., Lizasoain, L., López, E., y Navarro, E. (2014). Participación familiar y clima escolar en los centros de Educación Infantil, Educación Primaria y Educación Secundaria Obligatoria. En Ministerio de Educación, Cultura y Deporte. (Eds.), La participación de las familias en la educación escolar (pp. 181-195). Madrid, España: Secretaría General Técnica. doi: 10.13140/2.1.2654.8804

Cebolla Boado, H. (2014). Inmigración y educación: Los problemas tempranos de rendimiento escolar de los hijos de los inmigrantes. En J. Arango, D. Maya, y J. O. Alonso. (Dirs.), Anuario de la Inmigración en España 2013 (edición 2014). Inmigración y Emigración: mitos y realidades (pp. 163-184). Barcelona, España: CIDOB.

Coelho, E. (2006). Enseñar y aprender en escuelas multiculturales: Una aproximación integrada. Barcelona, España: Horsori.

Coelho, E., Serra, J., y Oller, J. (2013). Lenguaje y aprendizaje en el aula multilingüe. Barcelona, España: Horsori.

Collet-Sabé, J., Besalú, X., Feu, J., y Tort, A. (2014). Escuelas, familias y resultados académicos. Un nuevo modelo de análisis de las relaciones entre docentes y progenitores para el éxito de todo el alumnado. Profesorado, 18(2), 7-33.

Cortina, A. (1993). Ética aplicada y democracia radical. Madrid, España: Tecnos.

Creswell, J. W. (2009). Research design: Qualitative, quantitative and mixed approaches (3a. ed.). Thousand Oaks CA, EE. UU.: SAGE.

Debarbieux, E. (2017). L'école face à la violence: décrire, expliquer, agir. Cahiers Pedagogiques 538, 70-72.

Del Rincón, D., Arnal, J., La Torre, A., y Sans, A. (1995). Técnicas de investigación en Ciencias Sociales. Madrid, España: Dyckinson.

Demeuse, M., Frandji, D., Greger, D., \& Rochex, J-Y. (Ed.). (2012). Educational Policies and Inequalities in Europe. London, UK: Palgrabe Macmillan.

Espinosa, L., y Pérez, J. (2013). Diagnóstico de oportunidades de mejora de la convivencia escolar. En M.T. Castilla, V.M. Martín, E. S. Vila, y A. M. Sánchez. (Eds.), Educación y cultura de paz en contextos educativos (pp. 588-598). Granada, España: Editorial GEU.

Etxeberria, F., Intxausti, N., y Joaristi, L. (2013). Factores que favorecen la implicación educativa de las familias inmigrantes con hijos en Educación. Revista de Psicodidáctica, 18(1), 109-136. doi: 10.1387/RevPsicodidact.5684

Eustat. (2017). Euskal Estatistika Erakundea - Instituto Vasco de Estadística. Recuperado de www.eustat.eus/ 
Diversidad de origen y socioeconómica en una escuela de Gipuzkoa: diálogo con las

familias

Nerea Alzola Maiztegi, Marta Quintas Quintas, Nekane Arratibel Insausti y Amelia Barquín

LÓPEZ

Flores, R. (2016). La transmisión intergeneracional de la pobreza: factores, procesos y propuestas para la intervención. Madrid, España: Fundación FOESSA.

Florin, A., et Guimard, P. (2017). La qualité de vie à l'école. Paris, France: Cnesco.

Freire, P. (1993). Pedagogía de la esperanza: un reencuentro con la pedagogía del oprimido. Madrid, España: Siglo XXI.

Fundación "la Caixa". (2010). Fracaso y abandono escolar en España (Colección estudios sociales, 29). Recuperado de https://multimedia.caixabank.es/lacaixa/ondemand/obrasocial/pdf/estudiossociales/vol29_completo_es.pdf

Fundación Encuentro. (2015). Informe España 2015: una interpretación de su realidad social. Recuperado de www.informe-espana.es/wp-content/uploads/2016/12/Informe_Espana_2015.pdf

Gomariz, M. A., Hernández, M. A., Parra, J., y García, M. P. (2015). Prácticas docentes en educación infantil que facilitan la participación familiar en el centro educativo. En J. J. Maquilón. y N. Orcajada. (Ed.), Investigación y acción educativa en infantil y primaria (pp. 161-172). Murcia, España: Editum Editores de la Universidad de Murcia.

Habermas, J. (1988). La Lógica de las Ciencias Sociales. Madrid, España: Tecnos.

Habermas, J. (1994). La teoría de la acción comunicativa, complementos y estudios previos. Madrid, España: Cátedra.

Habermas, J. (2006). Entre naturalismo y religión. Barcelona, España: Paidós.

Hernández, R., Fernández, C., y Baptista, P. (2014). Metodología de la Investigación. (6a. ed.). México: McGraw Hill.

Hopson, L. M., \& Lee, E. (2011). Mitigating the effect of family poverty on academic and behavioral outcomes: The role of school climate in middle and high school. Children and Youth Services Review, 33, 2221-2229. doi: 10.1016/j.childyouth.2011.07.006

Ikuspegi. (2017). Haur eta gazteen aniztasuna EAEn, (Oker izendatutako) bigarren belaunaldiak. Recuperado de http://www.ikuspegi.eus/documentos/investigacion/eus/ gazte_aniztasuna/P1_CAP2_cifrasEUS.pdf

Ikuspegi. (2018). Barómetro 2018. Percepciones y actitudes hacia la población de origen extranjero. Recuperado de www.ikuspegi.eus/documentos/barometros/2018/ bar_CAE_2018_RESUMEN_CAS.pdf

Intxausti, N. (2010). Expectativas e implicación educativa de las familias inmigrantes de escolares en Educación Primaria de la CAPV: bases para la intervención educativa (Tesis doctoral). Euskal Herriko Unibertsitatea, San Sebastian, España.

ISEI-IVEI. (2018). Ebaluazio diagnostikoa 2017: Txosten exekutiboa oinarrizko hezkuntzaren egoerari buruz (LHko 4. maila - DBHko 2. Maila). Berreskuratuta. http://www. isei-ivei.hezkuntza.net/c/document_library/get_file?uuid=c1213185-61d1-48efa36d-b3956d805805\&groupld=635622

Ladrón de Guevara, B. (2018). La participación de las familias en la educación. Participación Educativa, 8, 79-91.

Leiva, J. J. (2015). La educación intercultural. Construyendo escuela en la comunidad y comunidad en la escuela. En A. Escarbajal. (Ed.), Comunidades interculturales y democracia (pp. 85-98). Madrid, España: Narcea.

Leiva, J. J., y Escarbajal, A. (2011). La participación de las familias inmigrantes como fun- 
Diversidad de origen y socioeconómica en una escuela de Gipuzkoa: diálogo con las familias

Nerea Alzola Maiztegi, Marta Quintas Quintas, Nekane Arratibel Insausti y Amelia Barquín LÓPEZ

damento pedagógico en la construcción de la interculturalidad en la escuela. Educatio Siglo XXI, 29(2), 389-416.

Lippy, C. H. (2009). Christian Nation or Pluralistic Culture: Religion in American Life. In J. A. Banks., y C. M. Banks. (Eds.), Multicultural education: issues and perspectives (pp. 109-132). New York, USA: John Wiley \& Sons.

Maalouf, A. (1999). Identidades asesinas. Madrid, España: Alianza Editorial.

Murillo, F. J., y Martínez-Garrido, C. (2018). Magnitud de la segregación escolar por nivel socioeconómico en España y sus Comunidades Autónomas y comparación con los países de la Unión europea. Revista de Sociología de la Educación (RASE), 11(1), 37-58. doi: 10.7203/RASE.11.1.10129

Nieto, S., y González, J. (2002). Los valores en la Literatura Infantil. Estudio empírico: Técnicas y procedimientos de análisis. Valladolid, España: Aral.

OCDE. (2018). Equity in Education: Breaking Down Barriers to Social Mobility, PISA. Paris, France: OCDE.

Pàmies, J., y Bertrán, M. (2015). Factores de éxito de centros educativos en entornos desfavorecidos. En AIDIPE (Ed.), Investigar con y para la sociedad, vol. 1. (pp. 433-441). Cádiz, España: Bubok.

Perea, I., y López, B. (2010). No revueltos: la distancia de la nacionalidad en las representaciones sociales. Inguruak. Revista vasca de sociología y ciencia política, extra(0), 95-108. Recuperado de https://dialnet.unirioja.es/servlet/articulo?codigo=5045821

Riehl, C. J. (2000). The Principal's Role in Creating Inclusive Schools for Diverse Students: A Review of Normative, Empirical, and Critical Literature on the Practice of Educational Administration. Review of Educational Research, 70(1), 55-81. doi: 10.3102/00346543070001055

Ruiz Olabuénaga, J. I. (1999). Metodología de la investigación cualitativa (2a ed.). Bilbao, España: Universidad de Deusto.

Santos Rego, M. A., y Lorenzo, M. (2015). El éxito educativo desde la pedagogía intercultural. Formación con valor añadido para el mundo global. En A. Escarbajal. (Ed.), Comunidades interculturales y democracia (pp. 63-84). Madrid, España: Narcea.

Save the Children. (2015). Iluminando el futuro. Invertir en educación es luchar contra la pobreza infantil. Recuperado de https://www.savethechildren.es/sites/default/files/ imce/docs/pobreza-equidad-educativa-espana_iluminando-el-futuro.pdf

Save the Children. (2018). Mézclate conmigo. De la segregación socioeconómica a la educación inclusiva. Recuperado de https://www.savethechildren.es/sites/default/files/imce/docs/mezclate_conmigo.pdf

Simón, C., Giné, C., y Echeita, G. (2016). Escuela, Familia y Comunidad: Construyendo Alianzas para promover la Inclusión. Revista Latinoamericana de Educación Inclusiva, 10(1), 25-42.

Stanford CEPA. (2018). Educational opportunity in early and middle childhood: Variation by place and age (17-12). Retrieved from https://cepa.stanford.edu/sites/default/files/ wp17-12-v201803.pdf

Torralba, J. M. (2018, 11, 23). Una asignatura pendiente: la educación ética y del carácter en la universidad. Studia XXI. Recuperado de https://www.universidadsi.es/unaasignatura-pendiente-la-educacion-etica-y-del-caracter-en-la-universidad 
Diversidad de origen y socioeconómica en una escuela de Gipuzkoa: diálogo con las

familias

Nerea Alzola Maiztegi, Marta Quintas Quintas, Nekane Arratibel Insausti y Amelia Barquín

LÓPEZ

Unicef. (2011). À l'école des enfants heureux... enfin presque. Récupéré de www.unicef. fr/sites/default/files/userfiles/UNICEF_FRANCE_violences_scolaires_mars_2011.pdf

Verdeja, M. (2016). Reinventando a Paulo Freire: aportaciones para un modelo de escuela inclusiva e intercultural. Revista Nacional e Internacional de Educación Inclusiva, 9(3), 173-186.

Zay, D. (2012). L'éducation inclusive. Une réponse à l'échec scolaire? Paris, France: L'Harmattan. 
